\title{
Synthesis and Crystal Structure of $\mathrm{Nb}_{0.84} \mathrm{~N}$
}

\author{
Nancy Frenzel ${ }^{\mathrm{a}}$, Elisabeth Irran ${ }^{\mathrm{a}}$, Martin Lerch $^{\mathrm{a}}$, and Alexandra Buchsteiner ${ }^{\mathrm{b}}$ \\ a Institut für Chemie, Technische Universität Berlin, Straße des 17. Juni 135, 10623 Berlin, \\ Germany \\ b Helmholtz-Zentrum Berlin für Materialien und Energie, Hahn-Meitner-Platz 1, 14109 Berlin, \\ Germany
}

Reprint requests to Dr. Elisabeth Irran. Fax: +49 30314 79656. E-mail: elisabeth.irran@tu-berlin.de

Z. Naturforsch. 2011, 66b, 1-6; received August 11, 2010

\begin{abstract}
A new compound of the composition $\mathrm{Nb}_{0.84} \mathrm{~N}$ was prepared by ammonolysis of $\mathrm{NbO}_{2}$ at $1100{ }^{\circ} \mathrm{C}$. The crystal structure refinement was performed by the Rietveld method using X-ray and neutron powder diffraction data. $\mathrm{Nb}_{0.84} \mathrm{~N}$ crystallizes in the trigonal space group $R \overline{3} m$ (no. 166) with the lattice parameters $a=298.5(2)$ and $c=2384.3(4) \mathrm{pm}$. The niobium atoms form a close packing with a layer sequence which can be described by the Jagodzinski symbol $h h c$. The nitrogen atoms fill all octahedral voids. Along [001] a sequence of two layers of trigonal $\mathrm{NbN}_{6}$ prisms and one layer of $\mathrm{NbN}_{6}$ octahedra is formed. The nitrogen positions are fully occupied, the niobium positions only partially. $\mathrm{Nb}_{0.84} \mathrm{~N}$ is part of a family of crystal structures between the anti-NiAs and the $\mathrm{NaCl}$ type consisting of close-packed metal layers with varying stacking sequences.
\end{abstract}

Key words: Niobium Nitride, Synthesis, Neutron Powder Diffraction, Close Packing

\section{Introduction}

Metal nitrides are of increasing interest because of their unique chemical and physical properties. Today they are used in applications ranging from refractory ceramics and wear-resistant coatings to semiconductor devices for optoelectronics [1,2].

A number of niobium nitrides where niobium is surrounded either by octahedra or by trigonal prisms of nitrogen atoms is known from the literature since the early works of Brauer, Jander, and Esselborn [3-7]. For example, $\delta$ - NbN crystallizes in the $\mathrm{NaCl}$ type, and $\gamma-\mathrm{NbN}$ forms a tetragonal superstructure of the $\mathrm{NaCl}$ type [5]. Both phases are slightly deficient in nitrogen. $\delta$ - $\mathrm{NbN}_{0.95}$ crystallizes in the NiAs type where the nitrogen atoms form a hexagonal close packing, while in $\varepsilon$-NbN the nitrogen atoms form a close packing with a stacking sequence of $h c h c$ [7]. In all these compounds $\mathrm{Nb}$ is octahedrally coordinated by nitrogen atoms.

On the other hand, $\delta^{\prime}-\mathrm{Nb}_{0.95} \mathrm{~N}$ crystallizes in the anti-NiAs type where nitrogen atoms form layers of prisms which are filled with $\mathrm{Nb}$ or remain empty [57]. $\mathrm{Nb}_{2} \mathrm{~N}$ also exhibits the anti-NiAs type, but the position of $\mathrm{N}$ is only half occupied [5,6]. While in the anti$\mathrm{NiAs}$ type filled and empty prisms alternate in neighboring layers, in $\mathrm{Nb}_{0.9} \mathrm{~N}$ and $\mathrm{NbN}_{0.85}$ the filled prisms lie above each other in every layer $[5,6]$. Tetragonal
$\mathrm{Nb}_{4} \mathrm{~N}_{5}$ shows a defect $\mathrm{NaCl}$-type structure with niobium vacancies $[8,9]$. Finally, $\mathrm{Nb}_{5} \mathrm{~N}_{6}$ should be mentioned which consists of alternating layers of $\mathrm{NbN}_{6}$ octahedra (only partially filled) and $\mathrm{NbN}_{6}$ prisms [8]. As shown by the above-mentioned compositions, niobium nitrides can be deficient both of nitrogen $\left(\mathrm{NbN}_{1-x}\right)$ and of niobium $\left(\mathrm{Nb}_{1-y} \mathrm{~N}\right)$. In this contribution we present a new niobium nitride synthesized by ammonolysis of niobium(IV) oxide at high temperatures.

\section{Experimental Section}

An alumina boat containing $2 \mathrm{~g}$ niobium(IV) oxide (Alfa Aesar, 99+\% metal base) was placed in an alumina tube inside a horizontal tube furnace (Gero $\mathrm{F} 70-500$ ). The new compound was obtained by reaction of $\mathrm{NbO}_{2}$ with watersaturated ammonia gas at $1100{ }^{\circ} \mathrm{C}$ for $76 \mathrm{~h}$. The flow rate was $10 \mathrm{~L} \mathrm{~h}^{-1}$. This procedure resulted in a grey powder with a silvery gloss. Nitrogen and oxygen contents were determined using a LECO TC-300 / EF-300 N/O analyzer (hot gas extraction). The accuracy (relative uncertainty) is about $2 \%$ of the N/O present.

As the new phase was only obtained as a powder, powder diffraction methods were used to determine the crystal structure. Diffraction experiments were performed with a Siemens D5000 diffractometer (Bragg-Brentano geometry, $\mathrm{Cu} K_{\alpha 1}$ radiation, $\lambda=154.06 \mathrm{pm}$, position sensitive detector) at r.t. The sample was fixed on a flat silicon sample holder. 
As the positions of the nitrogen atoms were difficult to refine in the presence of the heavier niobium atoms using X-ray methods, a neutron powder diffraction experiment was performed. Neutron diffraction patterns were recorded using the neutron powder diffractometer E6 at the BERII reactor of the Helmholtz-Zentrum Berlin für Materialien und Energie. The incident neutron wavelength was $244.6 \mathrm{pm}$. The area detector of the instrument covers an angular range of $2 \theta=18-105^{\circ}$. The sample container was a vanadium cylinder with a diameter of $6 \mathrm{~mm}$. All data were collected at r. t. (293 K).

Temperature-dependent X-ray diffraction measurements (samples in $\mathrm{SiO}_{2}$-glass capillaries under nitrogen) were carried out using a Stoe STADI-P powder diffractometer (MoK $K_{\alpha 1}$ radiation, $\lambda=70.93 \mathrm{pm}$, imaging plate detector) with a graphite heated resistance furnace.

\section{Results and Discussion}

By reaction with water-saturated ammonia gas at $1100{ }^{\circ} \mathrm{C}$ a new niobium nitride was synthesized. Temperature-dependent X-ray powder diffraction measurements have clearly shown that the new phase is stable at least up to $1000{ }^{\circ} \mathrm{C}$ (Fig. 1).

N/O analysis of the obtained powder showed 15.2 mass- $\%(\mathrm{~m}-\%)$ nitrogen and $0.47 \mathrm{~m}-\%$ oxygen. Rietveld refinements of the powder diffraction data pointed to the presence of two impurity phases. The minor impurity phase $(\sim 3.5 \mathrm{~m}-\%)$ shows a diffraction pattern similar to that of a $\mathrm{NbN}$ phase only known from thin films [11]. It can be assumed that due to the small content of this phase it is stabilized by the matrix. The major impurity phase $(\sim 8.8 \mathrm{~m}-\%)$ has a lattice
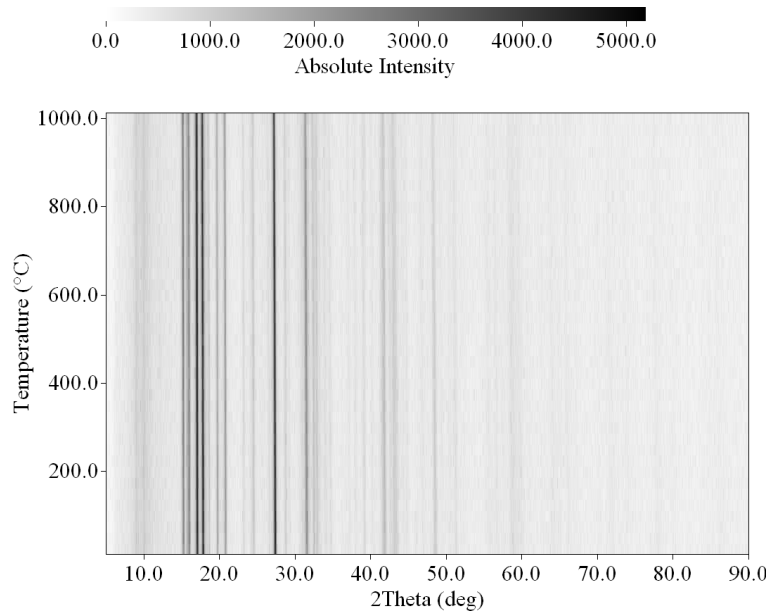

Fig. 1. Temperature-dependent X-ray powder diffraction patterns of $\mathrm{Nb}_{0.84} \mathrm{~N}\left(\mathrm{MoK} K_{\alpha 1}\right.$ radiation, wavelength $\left.70.93 \mathrm{pm}\right)$ up to $1000{ }^{\circ} \mathrm{C}$. The sample remains stable over the entire temperature range.

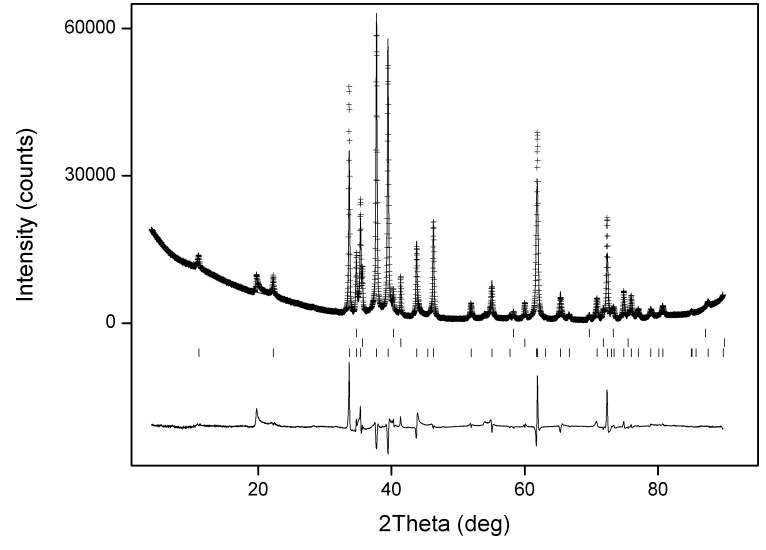

Fig. 2. Observed (crosses) and calculated (line) X-ray powder diffraction patterns of $\mathrm{Nb}_{0.84} \mathrm{~N}\left(\mathrm{Cu} K_{\alpha 1}\right.$ radiation, wavelength $154.06 \mathrm{pm}$ ) and difference profiles of the Rietveld refinement. The lower row of vertical lines gives possible peak positions, the upper rows those of $\mathrm{NbN}_{0.71} \mathrm{O}_{0.23}$ and $\mathrm{NbN}$, respectively.

constant of $436.5 \mathrm{pm}$, which lies between the values of $\mathrm{NbN}_{0.43} \mathrm{O}_{0.42}$ (434.3 pm [12]) and of $\mathrm{NbN}_{0.9} \mathrm{O}_{0.1}$ (438.2 pm [7]). Therefore a composition of about $\mathrm{NbN}_{0.71} \mathrm{O}_{0.23}$ is estimated for this impurity. Respecting these phases for the calculation of the stoichiometry of the main phase, an $\mathrm{Nb}: \mathrm{N}$ ratio of $\sim 0.75: 1$ is found.

The main phase of the obtained diffraction patterns (Fig. 2) can be indexed with a rhombohedral unit cell with a small $a$ and a large $c$ lattice parameter, 298.5(2) and $2384.3(4) \mathrm{pm}$, respectively (hexagonal setting). A search in the literature revealed three compounds with similar lattice constants and the rhombohedral space group $R \overline{3} m\left(\eta-\mathrm{Ti}_{3} \mathrm{~N}_{1.29}\right.$ [13], $\eta-\mathrm{Hf}_{3} \mathrm{~N}_{2}$ [14, 15], $\mathrm{Th}_{3} \mathrm{~N}_{4}$ [16]). Because $\eta-\mathrm{Hf}_{3} \mathrm{~N}_{2}$ has lattice constants closest to the new phase, its atomic coordinates were used as input for the Rietveld refinement (program GSAS [17]).

As discussed below in detail, the crystal structure contains two non-equivalent $\mathrm{Nb}$ atoms, one being octahedrally coordinated by nitrogen, and the other surrounded by six nitrogen atoms forming a trigonal prism. Refinements of the site occupation factors (X-ray data) have indicated that the sites of the niobium atoms are not fully occupied. When the occupation of the $\mathrm{N}$ positions was fixed at $100 \%$, the site occupation factor of the octahedral position of niobium was found to be smaller $(x=0.65(1))$ than that of the position surrounded by a trigonal prism $(x=$ 0.94(1)). From these results the composition of the new compound was calculated to $\sim \mathrm{Nb}_{0.87} \mathrm{~N}$. This is in 
Table 1. Crystallographic data for $\mathrm{Nb}_{0.84} \mathrm{~N}$.

\begin{tabular}{|c|c|c|}
\hline & Neutron data & X-Ray data \\
\hline$\overline{M_{\mathrm{r}}, \mathrm{g} \mathrm{mol}^{-1}}$ & 92.05 & 92.36 \\
\hline Crystal system & \multicolumn{2}{|c|}{ — trigonal — } \\
\hline Space group & \multicolumn{2}{|c|}{$-R \overline{3} m($ no. 166$)-$} \\
\hline Radiation; $\lambda, \mathrm{pm}$ & neutrons; 244.6 & $\mathrm{Cu} K_{\alpha 1} ; 154.06$ \\
\hline Temperature, ${ }^{\circ} \mathrm{C}$ & $\sim 22$ & $\sim 22$ \\
\hline Lattice constants & & \\
\hline$a, \mathrm{pm}$ & $298.5(2)$ & 299.49(1) \\
\hline$c, \mathrm{pm}$ & $2384.3(4)$ & $2392.2(1)$ \\
\hline$V, \times 10^{6} \mathrm{pm}^{3}$ & 184.01(17) & $185.82(1)$ \\
\hline$Z$ & \multicolumn{2}{|c|}{9} \\
\hline$\rho_{\text {calcd }}, \mathrm{g} \mathrm{cm}^{-3}$ & 7.47 & 7.43 \\
\hline $\begin{array}{l}\text { Profile range, deg } \\
R \text { values }\end{array}$ & $3 \leq 2 \theta \leq 105$ & $5 \leq 2 \theta \leq 90$ \\
\hline$w R_{\mathrm{p}}$ & 0.084 & 0.120 \\
\hline$R_{\mathrm{p}}$ & 0.061 & 0.066 \\
\hline$R_{\mathrm{F}}^{2}$ & 0.035 & 0.143 \\
\hline
\end{tabular}

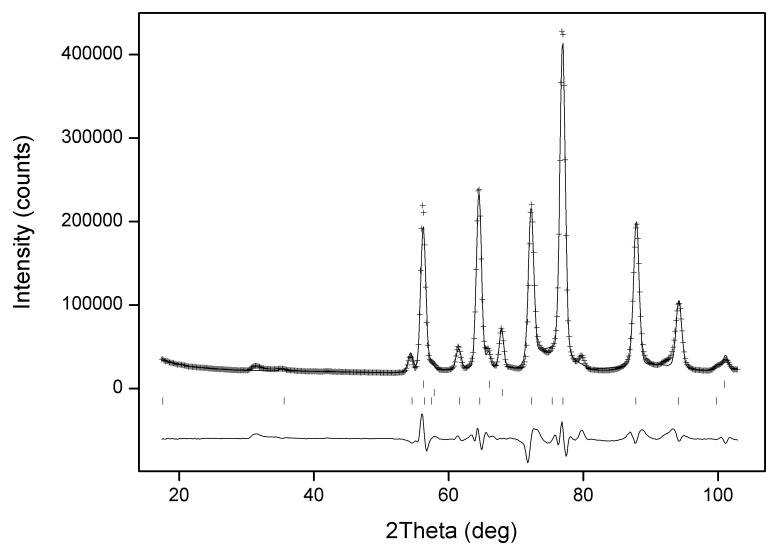

Fig. 3. Observed (crosses) and calculated (line) neutron powder diffraction patterns (wavelength $244.6 \mathrm{pm}$ ) and difference profiles of the Rietveld refinement of $\mathrm{Nb}_{0.84} \mathrm{~N}$. The lower row of vertical lines gives possible peak positions, the upper rows those of $\mathrm{NbN}_{0.71} \mathrm{O}_{0.23}$ and $\mathrm{NbN}$, respectively.

fair agreement with the stoichiometric formula derived from $\mathrm{N} / \mathrm{O}$ analysis which gave $\mathrm{Nb}_{0.75} \mathrm{~N}$.

Refinement of the neutron powder diffraction data (Fig. 3) confirmed the results of the X-ray diffraction experiments. For this method, the site occupation factors are $x=0.62(1)$ for the octahedral position and $x=0.95(1)$ for the trigonal prismatic position. Thus the composition can be calculated to $\sim \mathrm{Nb}_{0.84} \mathrm{~N}$. As the position and site occupation of nitrogen is more accurate for the neutron diffraction data than for the X-ray data, as of now we will refer to the composition of the new phase as $\mathrm{Nb}_{0.84} \mathrm{~N}$. Crystallographic data are summarized in Table 1, the atomic coordinates from the neutron powder diffraction experiment are listed in Table 2 , and bond lengths and angles in Table 3.
Table 2. Atomic positions, isotropic displacement parameters ${ }^{\mathrm{a}}\left(\mathrm{pm}^{2}\right)$ and site occupation factors SOF for $\mathrm{Nb}_{0.84} \mathrm{~N}$ (neutron data).

\begin{tabular}{lccllll}
\hline Atom & W.-position & $x$ & $y$ & $z$ & $U_{\text {iso }}$ & SOF \\
\hline $\mathrm{Nb} 1$ & $3 a$ & 0 & 0 & 0 & $239(39)$ & $0.62(1)$ \\
$\mathrm{Nb} 2$ & $6 c$ & 0 & 0 & $0.2255(2)$ & $290(33)$ & $0.95(1)$ \\
$\mathrm{N} 1$ & $3 b$ & 0 & 0 & $1 / 2$ & $248(28)$ & 1 \\
$\mathrm{~N} 2$ & $6 c$ & 0 & 0 & $0.3870(1)$ & $310(43)$ & 1 \\
\hline${ }^{\mathrm{a}} U_{\text {iso }}$ is defined as $\exp \left[-8 \pi^{2} U\left(\sin ^{2} \theta / \lambda^{2}\right)\right]$. & &
\end{tabular}

Table 3. Bond lengths (pm) and angles (deg) for $\mathrm{Nb}_{0.84} \mathrm{~N}$ (neutron data).

\begin{tabular}{llllrl}
\hline Nb1-N2 & $211.8(1)$ & $6 \times$ & N2-Nb1-N2 & $90.28(1)$ & $6 \times$ \\
Nb2-N1 & $223.3(1)$ & $3 \times$ & N2-Nb1-N2 & $89.72(1)$ & $6 \times$ \\
Nb2-N2 & $221.1(1)$ & $3 \times$ & N2-Nb1-N2 & 180 & $3 \times$ \\
& & & N2-Nb2-N2 & $84.49(1)$ & $6 \times$ \\
& & & N2-Nb2-N2 & $77.44(1)$ & $3 \times$ \\
& & & N1-Nb2-N2 & $134.07(1)$ & $6 \times$ \\
\hline
\end{tabular}

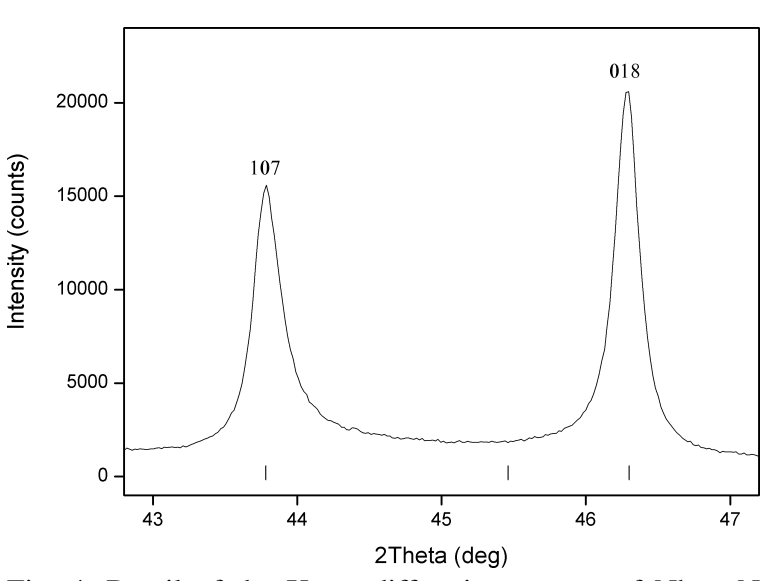

Fig. 4. Detail of the X-ray diffraction pattern of $\mathrm{Nb}_{0.84} \mathrm{~N}$ showing the asymmetric peak shape of a reflection with an index of the $10(3 n+1)$ type (diffraction band to higher diffraction angles) and one with an index of the $01(3 n+2)$ type (diffraction band to lower diffraction angles), respectively.

During refinement some deviations between calculated and observed intensities were detected for some of the diffraction peaks. At closer examination the peaks with indices $10(3 n+1)$ and $02(3 n+1)$ show a diffraction band ("tailing") to higher diffraction angles, while, in contrast, the peaks with indices $01(3 n+2)$ and $20(3 n+2)$ show a diffraction band to lower diffraction angles (Fig. 4). This is caused by stacking faults which can not be accounted for by common Rietveld refinement programs.

The new compound described here consists of closepacked $\mathrm{Nb}$ layers, the packing sequence along the $c$ axis being ABABCBCACA or $(h h c)_{3}$ after Jagodzinski [18]. The $\mathrm{N}$ atoms form the non-close-packed se- 
Table 4. Members of the NiAs- $\mathrm{NaCl}$ and anti-NiAs-NaCl families; $n$ is the number of close-packed layers in the unit cells.

\begin{tabular}{|c|c|c|c|c|}
\hline NiAs-NaCl family & anti-NiAs-NaCl family & $\begin{array}{l}\text { Jagodzinski } \\
\text { notation }\end{array}$ & $n$ & Space group \\
\hline NiAs [20], TiS [21] etc. & $\delta^{\prime}-\mathrm{Nb}_{0.95} \mathrm{~N}[10], \mathrm{PtB}[22]$ & $h_{2}$ & 2 & $P 6_{3} / m m c$ \\
\hline TiP [24], $\mathrm{Ti}_{3} \mathrm{~S}_{4}$ [33], $\varepsilon-\mathrm{NbN}$ [7], HfP [31], TiAs [32] & $\begin{array}{l}\mathrm{Ta}_{3} \mathrm{MnN}_{4} \text { [23], } \mathrm{ScNbN}_{1-x} \text { [25], } \mathrm{ScTaN}_{1-x} \text { [26], } \\
\mathrm{BaCeN}_{2} \text { [27], } \mathrm{Li}_{0.84} \mathrm{~W}_{1.16} \mathrm{~N}_{2} \text { [28], } \mathrm{TIInS}_{2} \text {-III [29], } \\
\mathrm{CsPrS}_{2} \text {-II [30] }\end{array}$ & $(h c)_{2}$ & 4 & $P 6_{3} / m m c$ \\
\hline $\mathrm{Ti}_{3} \mathrm{SiC}_{2}$ [35] & $\eta-\mathrm{Mo}_{3} \mathrm{C}_{2}[34]$ & $(h c c)_{2}$ & 6 & $\mathrm{P6}_{3} / \mathrm{mmc}$ \\
\hline $\mathrm{Ti}_{5.36} \mathrm{~S}_{8}[37]$ & - & hhchcchc & 8 & $P \overline{3} m 1$ \\
\hline TiS-9R [37], $\mathrm{Zr}_{2.29} \mathrm{Te}_{2} \mathrm{As}$ [38], $\mathrm{NaZr}_{2} \mathrm{Te}_{2} \mathrm{As}$ [38] & $\eta-\mathrm{Ti}_{3} \mathrm{~N}_{1.29}[13], \eta-\mathrm{Hf}_{3} \mathrm{~N}_{2}[14], \mathrm{Ta}_{2} \mathrm{VC}_{2}[36], \mathrm{Nb}_{0.84} \mathrm{~N}$ & $(h h c)_{3}$ & 9 & $R \overline{3} m$ \\
\hline $\mathrm{Ti}_{4} \mathrm{~S}_{5}[46]$ & - & $(\text { hhchc })_{2}$ & 10 & $\mathrm{PG}_{3} / \mathrm{mmc}$ \\
\hline $\begin{array}{l}\mathrm{Ti}_{7.5} \mathrm{~S}_{12}-12 \mathrm{R}[41], \mathrm{TiS}_{1.71} \text { [42], } \mathrm{Sc}_{2} \mathrm{Te}_{3} \text { [43], } \\
\mathrm{FeIn}_{2} \mathrm{~S}_{2} \mathrm{Se}_{2}[44], \mathrm{Li}_{0.62} \mathrm{CoO}_{2}[45]\end{array}$ & $\zeta-\mathrm{V}_{4} \mathrm{C}_{2.66}[39], \zeta-\mathrm{Hf}_{4} \mathrm{~N}_{3}[14], \zeta-\mathrm{Ti}_{4} \mathrm{~N}_{2.333}[40]$ & $(h h c c)_{3}$ & 12 & $R \overline{3} m$ \\
\hline
\end{tabular}

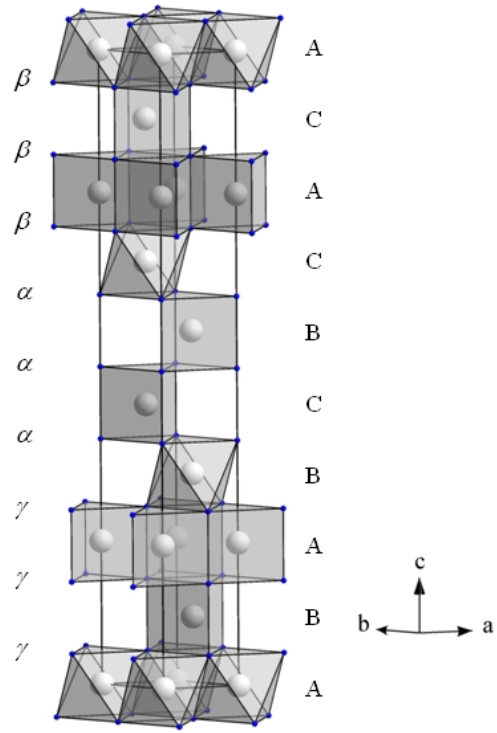

Fig. 5. Crystal structure of $\mathrm{Nb}_{0.84} \mathrm{~N}$. Partially filled sites are shown fully occupied, and coordination polyhedra around the metals (balls) are given. A, B, and C denote layers of the niobium atoms, $\alpha, \beta$, and $\gamma$ layers of nitrogen atoms.

quence $\gamma \gamma \gamma \alpha \alpha \alpha \beta \beta \beta$ (Fig. 5). As a consequence, layers of edge-sharing $\mathrm{NbN}_{6}$ octahedra alternate with two layers of $\mathrm{NbN}_{6}$ edge-sharing prisms. Both sorts of layers are connected via edges. Fig. 6 shows the coordination polyhedra around the two sorts of $\mathrm{Nb}$, and in Table 2 some interatomic distances and angles are listed. The distances $\mathrm{Nb}-\mathrm{N}$ of 212, 223, and $221 \mathrm{pm}$ are in good agreement with values for typical $\mathrm{Nb}-\mathrm{N}$ distances of 210 to 230 pm given in the Inorganic Crystal Structure Database ICSD [19].

$\mathrm{Nb}_{0.84} \mathrm{~N}$ is part of a family of compounds with crystal structures derived from both the anti-NiAs and the $\mathrm{NaCl}$ type. These compounds consist of close-packed metal atoms with varying stacking sequences with anions in all octahedral voids. The coordination polyhe-
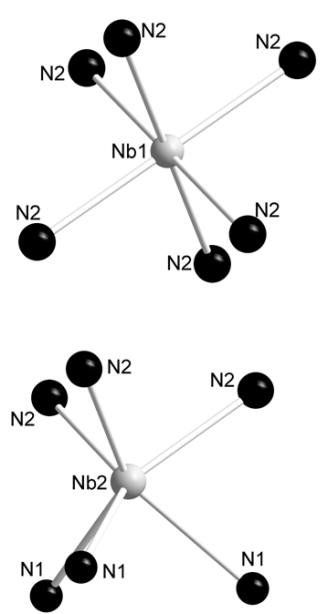

Fig. 6. Coordination polyhedra around $\mathrm{Nb} 1$ and $\mathrm{Nb} 2 . \mathrm{Nb} 1$ is octahedrally coordinated by six $\mathrm{N}$ atoms, $\mathrm{Nb} 2$ by six $\mathrm{N}$ atoms forming a trigonal prism.

dra around the metals are trigonal prisms or octahedra which are arranged in layers of exclusively one type of these polyhedra. All types of this family can also be described as anti-types of the family of compounds between the NiAs- [20] and NaCl-type structures. For this second family the packing of anions is closest, and only layers of octahedra around the cations are stacked. Table 4 lists some examples of both families. Fig. 7 shows some of these structures in comparison to that of $\mathrm{Nb}_{0.84} \mathrm{~N}$. The simplest stacking sequence is observed for the NiAs type with about 60 known members (mainly pnictides and chalcogenides like TiS [21]) and the anti-NiAs type with $\delta$-NbN [10] and PtB [22]. The $\mathrm{Ta}_{3} \mathrm{MnN}_{4}$ type [23] is equivalent with the antiTiP type [24], the packing of the metals being $(h c)_{2}$. There are other nitrides with this type $\left(\mathrm{ScNbN}_{1-x}\right.$ [25], $\mathrm{ScTaN}_{1-x}$ [26], $\mathrm{BaCeN}_{2}$ [27], and $\mathrm{Li}_{0.84} \mathrm{~W}_{1.16} \mathrm{~N}_{2}$ [28]), but also sulfides (TIInS $\mathrm{T}_{2}$-III [29], $\mathrm{CsPrS}_{2}$-II [30]) crystallize in this form. The TiP type is known for a 


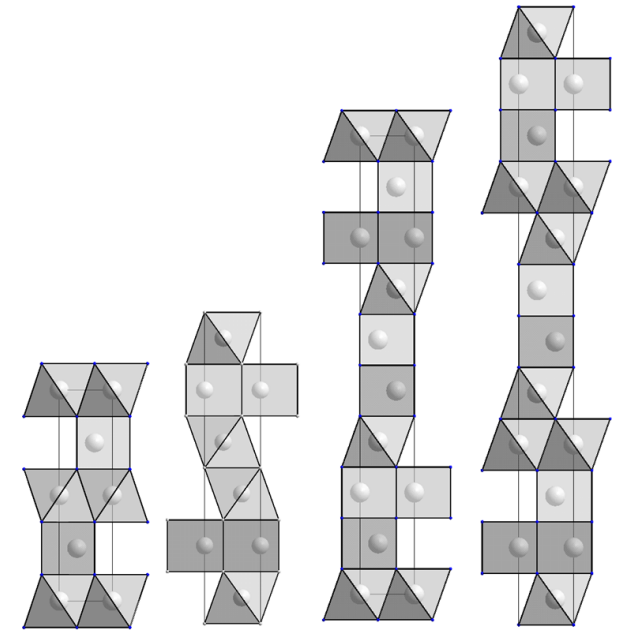

Fig. 7. Unit cells of $\mathrm{Ta}_{3} \mathrm{MnN}_{4}$ [23], $\eta-\mathrm{Mo}_{3} \mathrm{C}_{2}$ [34], $\mathrm{Nb}_{0.84} \mathrm{~N}$, and $\zeta-\mathrm{Hf}_{4} \mathrm{~N}_{3}$ [14]. Partially filled sites are shown fully occupied. Coordination polyhedra around the metals (balls) are given.

number of pnictides $[7,31,32]$ and for titanium sulfide $\mathrm{Ti}_{3} \mathrm{~S}_{4}$ [33]. In $\eta-\mathrm{Mo}_{3} \mathrm{C}_{2}$ [34], which forms the anti-type to the $\mathrm{Ti}_{3} \mathrm{SiC}_{2}$ type [35], the packing of the metals is $(h c c)_{2}$. The title compound $\mathrm{Nb}_{0.84} \mathrm{~N}$ crystallizes in the same stacking variant as $\eta-\mathrm{Hf}_{3} \mathrm{~N}_{2}[14,15]$ with the stacking period $(h h c)_{3}$, but with different defects. $\mathrm{Ta}_{2} \mathrm{VC}_{2}$ [36] and the high-temperature subnitride $\eta-\mathrm{Ti}_{3} \mathrm{~N}_{1.29}$ [13] crystallize in the same stacking variant, whereas TiS-9R forms the anti-type [35]; isotypic with the latter are $\mathrm{Zr}_{2.29} \mathrm{TeAs}$ and $\mathrm{NaZr}_{2} \mathrm{Te}_{2} \mathrm{As}$ [38]. In $\zeta-\mathrm{V}_{4} \mathrm{C}_{3}$ [39], $\zeta-\mathrm{Hf}_{4} \mathrm{~N}_{3}$ [14], and $\zeta-\mathrm{Ti}_{4} \mathrm{~N}_{2.333}$ [40] the metals show the close-packing variant $(h h c c)_{3}$, and therefore two layers of prisms alternate with two layers of octahedra. The anti-type is $\mathrm{Ti}_{7.5} \mathrm{~S}_{12}-12 \mathrm{R}$, and some other examples are listed in Table 4 [41-45]. No antitypes were found for the $\mathrm{Ti}_{5.36} \mathrm{~S}_{8}$ type [37] (hhchcchc), for $\mathrm{Ti}_{4} \mathrm{~S}_{5}$ [46] $\left((h h c h c)_{2}\right), \mathrm{Ti}_{6.9} \mathrm{~S}_{9}-18 \mathrm{H}$ [47] and all stacking sequences of $\mathrm{Ti}_{1-x} \mathrm{~S}$ with higher complexity, which are not listed here.

In both type- and anti-type-families a partial occupation of the anion or metal sites is often observed. From titanium sulfides it is known that completely and partially occupied metal layers occur, which can be described by occupation waves [46]. Maxima of these waves are near $h$-packed layers, and therefore their metal content increases with increasing proportions of $h$-packed layers. In carbides crystallizing in anti-types of titanium sulfides ( $c$-packed layers of the metal atoms) the carbon positions are fully occupied while every $h$-packed layer is half occupied. Within the group of nitrides no such trend is seen.

As mentioned above, $\mathrm{Th}_{3} \mathrm{~N}_{4}$ has similar lattice parameters and the same space group as the title compound. In contrast to trigonal prisms, which are the basic building units in $\mathrm{Nb}_{0.84} \mathrm{~N}$, it exhibits single-capped trigonal prisms [16]. Refinements of the title compound starting with the atomic positions of $\mathrm{Th}_{3} \mathrm{~N}_{4}$ were not successful. Therefore no isotypism of the two compounds can be assumed.

Magnetic, electric, or mechanical properties have not been determined yet, because the new compound could not be synthesized without impurities.
[1] F] L. Riley, J. Am. Ceram. Soc. 2000, 83, 245-265.

[2] F. A. Ponce, D. P. Bour, Nature 1997, 386, 351 - 359.

[3] G. Brauer, J. Jander, R. Esselborn, J. Less-Common Met. 1960, 2, 131-137.

[4] G. Brauer, R. Esselborn, Z. Anorg. Allg. Chem. 1961, $308,52-61$.

[5] G. Brauer, R. Esselborn, Z. Anorg. Allg. Chem. 1961, $309,151-170$.

[6] G. Brauer, J. Jander, Z. Anorg. Allg. Chem. 1952, 270, $160-178$.

[7] N Schönberg, Acta Chem. Scand. 1954, 8, 208 - 212.

[8] N. Terao, J. Less-Common Met. 1971, 23, 159-169.

[9] R. Marchand, F. Tessier, F. J. DiSalvo, J. Mater. Chem. 1999, 9, 297-304.

[10] N] Terao, Japan. J. Appl. Phys. 1965, 4, 353-367.

[11] R. E. Treece, M. S. Osofsky, E. F. Skelton, S. B. Qadri, J. S. Horwitz, D. B. Chrisey, Phys. Rev. B 1995, 51, 9356-9359.
[12] S. Yamamoto, Y. Ohashi, Y. Masubuchi, T. Takeda, T. Motohashi, S. Kikkawa, J. Alloys Compd. 2009, 482, $160-163$.

[13] W] Lengauer, J. Less-Common Met. 1986, 125, 127 134.

[14] E. Rudy, Metall. Trans. 1979, 1, 1249-1252.

[15] W. Lengauer, D. Rafaja, R. Täubler, C. Kral, P. Ettmayer, Acta Metall. Mater. 1993, 41, 3505-3514.

[16] R. Benz, W. H. Zachariasen, Acta Crystallogr. 1966, $21,838-840$.

[17] A. C. Larson, R. B. von Dreele, Gsas, General Structure Analysis System, Report LAUR 86-748, Los Alamos National Laboratory, Los Alamos, NM (USA) 1990.

[18] H] Jagodzinski, Acta Crystallogr. 1949, 2, 201 - 207.

[19] ICSD, Inorganic Crystal Structure Database (Set $06-$ 2), Fachinformationszentrum Karlsruhe, EggensteinLeopoldshafen (Germany) 2006. 
[20] G. Aminoff, Z. Kristallogr. 1923, 58, $203-219$.

[21] G. Hägg, N. Schönberg, Ark. Kemi 1954, 7, 371 - 380.

[22] B. Aronsson, E. Stenberg, J. Aselius, Acta Chem. Scand. 1960, 14, 733-741.

[23] N. Schönberg, Acta Chem. Scand. 1954, 8, 213-220.

[24] N. Schönberg, Acta Chem. Scand. 1954, 8, 226-239.

[25] W. Lengauer, J. Solid State Chem. 1989, 82, 186-191.

[26] W] Lengauer, P. Ettmayer, J. Less-Common Met. 1988, $141,157-162$.

[27] O. Seeger, J. Strähle, Z. Naturforsch. 1994, 49b, 1169 1174.

[28] S. Kaskel, D. Hohlwein, J. Straehle, J. Solid State Chem. 1998, 138, 154-159.

[29] K. J. Range, G. Engert, W. Mueller, A. Weiss, Z. Naturforsch. 1974, 29b, $181-185$.

[30] W. Bronger, W. Brüggemann, M. von der Ahe, D. Schmitz, J. Alloys Compd. 1993, 200, $205-210$.

[31] W. Jeitschko, H. Nowotny, Monatsh. Chem. 1962, 93, $1107-1109$.

[32] K. Lukaszewicz, W. Trzebiatowski, Bull. Acad. Pol. Sci., Ser. Chim. 1954, 2, 277-279.

[33] H. Hahn, B. Harder, Z. Anorg. Allg. Chem. 1956, 288, $241-256$

[34] H. Nowotny, E. Parthé, R. Kieffer, F. Benesowsky, Monatsh. Chem. 1954, 85, 255-272.
[35] W] Jeitschko, H. Nowotny, Monatsh. Chem. 1967, 98, $329-337$.

[36] E. Rudy, J. Less-Common Met. 1970, 20, 49-55.

[37] E. Tronc, M. Huber, J. Phys. Chem. Solids 1973, 34, $2045-2058$.

[38] C. C. Wang, C. Eylem, T. Hughbanks, Inorg. Chem. 1998, 37, 390-397.

[39] K Yvon, E. Parthe, Acta Crystallogr. B 1970, 26, 149 153.

[40] W] Lengauer, P. Ettmayer, J. Less-Common Met. 1986, $120,153-159$.

[41] E. Flink, G. A. Wiegers, F. Jellinek, Recl. Trav. Chim. Pays Bas Belgique 1966, 85, 869-872.

[42] E. Tronc, R. Moret, J. J. Legendre, M. Huber, Acta Crystallogr. B 1975, 31, 2800-2804.

[43] J. G. White, J.P. Dismukes, Inorg. Chem. 1965, 4, $1760-1763$.

[44] S. Reil, H. Haeuseler, J. Alloys Compd. 1998, 270, 83 87.

[45] A Mendiboure, C. Delmas, P. Hagenmuller, Mater. Res. Bull. 1984, 19, 1383 - 1392.

[46] G. A. Wiegers, F. Jellinek, J. Solid State Chem. 1979, $1,519-525$.

[47] M. Onoda, H. Wada, J. Less-Common Met. 1987, 132, $195-207$. 